\title{
The Use of Aspirin for the Treatment of Malignancies: Review Study
}

\section{Dana Ayman Abdel Ra'ouf Alnsour}

The University of Jordan, Jordan

\author{
Ahed J Alkhatib
}

Jordan University of Science and technology, Jordan

\section{doi: 10.19044/esj.2016.v12n36p430 URL:http://dx.doi.org/10.19044/esj.2016.v12n36p430}

\begin{abstract}
The present review study reviewed the literature for the possible therapeutic roles of aspirin against tumors. Aspirin has various therapeutic properties among which is the anti-inflammatory property. Epidemiological studies have proved the efficacy of long term use of aspirin in reducing the incidence of colorectal cancer by up to $30 \%$, and the cancer risk as well. Although no exact mechanism has been entirely proposed so far to explain the antineoplastic effect of aspirin against cancer, two mechanisms have been under focus, the first is related to its anti-inflammatory properties which are thought to suppress the inflammatory mediators and to inhibit carcinogenic mechanisms, and the other mechanism is through the deactivation of COX2. We would like to raise the possibility for aspirin to be regularly involved in preventive mechanisms.
\end{abstract}

Keywords: Aspirin, cancer, tumor, inflammatory, COX2.

\section{Introduction}

\section{An overview of aspirin}

The history of aspirin synthesis and production has begun since 1897 when Bayer manufactured it (Jack, 1997). Aspirin has a simple chemical structure composed of a benzene ring attaching to an acetyl group and a carboxylic acid group (Logan, 2007). Aspirin is also called acetylsalicylic acid and it is one of the members in the group called non-steroidal antiinflammatory drugs (NSAIDs) (Vane and Botting, 2003). Aspirin has various therapeutic properties including analgesic, anti-pyretic, anti-thrombotic and anti-inflammatory (Poindexter, 2015). 


\section{Overview of cancer}

The definition of cancer implies the presence of malignant neoplasia that are characterized by uncontrolled growth of cells which usually have the ability to invade local or in other sites of the body. Cancers are classified according to the type of tissue or the primary site in which they are originated (Taber's Cyclopedic Medical Dictionary, 2013).

Epidemiological studies have pointed to the presence of 1.7 million new cancer cases in the United States in 2014, and the incidence of cancer is about 460 per 100,000 persons (Howlader et al., 2014). The most prevalent cancers among humans include lung, colorectal, prostate, and breast cancer (Siegel et al., 2013).

In the USA, cancer is in the second rank in causing death, and accounts for $25 \%$ deaths (Siegel et al., 2013). It has been reported that lung cancer, colorectal cancer, breast cancer, and prostate cancer are the most prevalent types of cancers (Howlader et al., 2014).

\section{Aspirin and colorectal cancer (CRC)}

According to the study of Burn and Sheth (2016), colorectal cancer (CRC) is considered among the most prevalent cancers in the Western countries and the second leading cause of mortality due to cancer in the UK and USA. The authors also expressed their views that systematic intake of aspirin has the ability to lower several cancer parameters including incidence, recurrence, metastasis and mortality.

Aspirin has been believed to act as chemopreventative treatment because authors showed its ability to lower the development of precancerous adenomas and CRC (Flossmann and Rothwell 2007; Cole et al., 2009).

Cancer studies have shown that the use of aspirin to be associated with risk reduction of developing adenoma by $30 \%$ and the development of CRC by 26\% (Cole et al., 2009; Cooper et al., 2010). These findings have been confirmed in vivo and in vitro on cancer cells, tumor tissue microenvironment and cytokines (Garcia-Albeniz and Chan, 2011).

According to Rothwell et al (2012), the daily intake of aspirin lowers overall cancer problems in cancer patients. The study of Gamba et al (2013) demonstrated the low doses intake of aspirin continuously to be associated with reduced incidence of melanoma among women. Other studies have indicated that patients who take aspirin have low prevalence of colorectal, esophageal, pancreatic, and lung cancer compared with who do not (Rothwell et al., 2012).

\section{Aspirin and COX-2}

The mechanism by which aspirin mediates its action against cancer cells is thought to be through the inhibition of cyclo-oxygenase enzymes 
(COX-1 and COX-2) which work to catalyze tissue-specific signaling lipids. Aspirin has the ability to inactivate these enzymes by acetylating serine residues (Thun, Jacobs, and Patrono, 2012).

The expression of COX-2 was reported in various tissues and can be induced in other tissues through inflammatory processes, wound healing and tumors. It has been shown that aspirin counteracts tumorigenesis through the action in the COX-2 pathway (Sostres, Gargallo, and Lanas, 2014). Another study by Chan et al (2007) showed that aspirin lowers the risk of CRC among persons who upregulates the expression of COX-2 in comparison with persons who do not.

It has been reported that the inhibition of $\mathrm{COX}-2$ activity in nucleated cells requires high doses of aspirin (>2,000 $\mathrm{mg}$ daily) (Chan et al., 2007; Sostres, Gargallo , and Lanas, 2014). Furthermore, it has been demonstrated that if the genes of either COX1 or COX2 are deleted, the formation of ntestinal polyp in a mouse model will be reduced (Sostres, Gargallo , and Lanas, 2014).

Several studies have focused on the mortality among patients with $\mathrm{CRC}$ and its relation with the use of aspirin. These studies have shown that the risk for CRC death was reduced among patients who used aspirin 75-1200 mg daily for at least 1 year (Farrell et al., 1991; Petoet al., 1988; Rothwell et al., 2010).

\section{The role of aspirin in targeting inflammation to counteract carcinogenesis}

Todoric et al (2016) conducted a study in view of some considerations among which is the association of inflammation with both the development and malignant progression of most cancers. There are extrinsic and intrinsic factors, due to inflammation, can stimulate cancer in general. The intake of aspirin can counteract these mechanisms and reduce the initiating of carcinogenesis.

According to Chan et al (2012), no exact mechanism has been proposed to explain its effects against carcinogenesis, but it is thought that this may due to its modulating role of inflammatory reactions and direct effect on tumor cells.

Aspirin can exert its anti-neoplastic effects through inhibiting prostaglandin $\mathrm{G} / \mathrm{H}$-synthase 2 (PGHS2) transcription, and prevention the conversion of PGHS 2 and COX2 from arachidonic acid to potentially tumourinducing prostaglandins. Aspirin can also decrease the expression of Sp1, Sp3 and Sp4 transcription factors, and vascular endothelial growth factor (VEGF), and by thus lowers tumor cell growth (Bae et al., 2003). According to the study of Liao et al (2012), aspirin has been only of beneficial effect in CRCs with a mutated, rather than wild-type PIK3CA gene which may demonstrate the 
effects of aspirin from other non-steroids. Proposing that salicylic acid has the antineoplastic property in aspirin, then dietary intake could be therapeutic (Paterson et al., 2007).

\section{Conclusion}

In this review study, we reviewed the literature for the use of aspirin as anti-cancer agent. May studies have shown its efficacy in reducing the development and incidence of cancers in general and particularly, the CRC. Suggested mechanisms rotate on the axis of inflammation and the inhibition of COX2.

\section{References:}

1. Bae Y. et al (2003). Molecular ordering of ROS production, mitochondrial changes, and caspase activation during sodium salicylate-induced apoptosis Free Radical Biology and Medicine, 34(4): 434- 442.

2. Chan AT, Ogino S, Fuchs CS (2007). Aspirin and the risk of colorectal cancer in relation to the expression of COX-2. N Engl $\mathrm{J}$ Med, 356(21):2131-42.

3. Chan, A. T., N. Arber, J. Burn, W. K. Chia, P. Elwood, M. A. Hull, R. F. Logan, P. M. Rothwell, K. Schror and J. A. Baron (2012). Aspirin in the chemoprevention of colorectal neoplasia: an overview. Cancer Prev Res (Phila) 5(2): 164-178.

4. Cole, B. F., R. F. Logan, S. Halabi, R. Benamouzig, R. S. Sandler, M. J. Grainge, S. Chaussade and J. A. Baron (2009). Aspirin for the chemoprevention of colorectal adenomas: meta-analysis of the randomized trials. J Natl Cancer Inst 101(4): 256-266.

5. Cooper, K., H. Squires, C. Carroll, D. Papaioannou, A. Booth, R. F. Logan, C. Maguire, D. Hind and P. Tappenden (2010). Chemoprevention of colorectal cancer: systematic review and economic evaluation. Health Technol Assess 14(32): 1-206.

6. Farrell B, Godwin J, Richards S, Warlow C (1991). The United Kingdom transient ischaemic attack (UK-TIA) aspirin trial: final results. J Neurol Neurosurg Psychiatry, 54:1044-54.

7. Flossmann, E. and P. M. Rothwell (2007). Effect of aspirin on longterm risk of colorectal cancer: consistent evidence from randomised and observational studies. Lancet 369(9573): 1603-1613. 
8. Gamba, C. A., Swetter, S. M., Stefanick, M. L., Kubo, J., Desai, M., Spaunhurst, K. M., Sinha, A. A., Asgari, M. M., Sturgeon, S., and Tang, J. Y. (2013). Aspirin is associated with lower melanoma risk among postmenopausal Caucasian women: the Women's Health Initiative. Cancer 119, 1562-1569.

9. Garcia-Albeniz, X. and A. T. Chan (2011). Aspirin for the prevention of colorectal cancer. Best Pract Res Clin Gastroenterol 25(4-5): 461472.

10. Howlader, N, Noone, AM, Krapcho, M, et al (2014). SEER Cancer Statistics Review, 1975-2011. Bethesda, MD: National Cancer Institute, PMID: None.

11. Jack DB (1997). One hundred years of aspirin. Lancet, 350:437-39.

12. Jelena Todoric, Laura Antonucci, Michael Karin (2016). Targeting Inflammation in Cancer Prevention and Therapy. Cancer Prev Res November 102016 DOI: 10.1158/1940-6207.CAPR-16-0209.

13. John Burn, Harsh Sheth (2016). The role of aspirin in preventing colorectal cancer. Br Med Bull, 119 (1): 17-

24.doi: 10.1093/bmb/ldw028.

14. Kevin Michael Poindexter (2015). Regulation of anti-proliferation in melanoma and breast cancer cells by small molecule phytochemicals and their derivatives. Ph. D dissertation. University of California, Berkeley.

15. Liao, X. et al (2012). Aspirin Use, Tumor PIK3CA Mutation, and Colorectal-Cancer Survival. New England Journal of Medicine, 367(17): 1596-1606.

16. Paterson TJ, Baxter G, Lawrence J, Duthie G (2006). Is there a role for dietary salicylates in health? Proc Nutr Soc, 65: 93-96.

17. Peto R, Gray R, Collins R, Wheatley K, Hennekens C, Jamrozik K, et al (1988). Randomised trial of prophylactic daily aspirin in British male doctors. Br Med J (Clin Res Ed), 296:313-6.

18. Richard Logan (2007). Commentary: Preventing colorectal cancer with aspirin-what next. International Journal of Epidemiology, 36:960-962.

19. Rothwell PM, Wilson M, Elwin CE, Norrving B, Algra A, Warlow CP, et al (2012). Long-term effect of aspirin on colorectal cancer incidence 
and mortality: 20-year follow-up of five randomised trials. Lancet, 376:1741-50.

20. Rothwell, P. M., Fowkes, F. G., Belch, J. F., Ogawa, H., Warlow, C. P., and Meade, T. W. (2011). Effect of daily aspirin on long-term risk of death due to cancer: analysis of individual patient data from randomized trials. Lancet 377, 31-41.

21. Rothwell, P. M., Price, J. F., Fowkes, F. G., Zanchetti, A., Roncaglioni, M. C., Tognoni, G., Lee, R., Belch, J. F., Wilson, M., Mehta, Z., and Meade, T. W. (2012). Short-term effects of daily aspirin on cancer incidence, mortality, and non-vascular death: analysis of the time course of risks and benefits in 51 randomised controlled trials. Lancet 379, 1602-1612.

22. Siegel R, Naishadham D, Jemal A (2013). Cancer statistics, 2013, CA Cancer J Clin, 63(1):11-30. PMID: 23335087.

23. Sostres C, Gargallo CJ, Lanas A (2014). Aspirin, cyclooxygenase inhibition and colorectal cancer. World J Gastrointest Pharmacol Ther 6;5(1):40-9.

24. Taber's Cyclopedic Medical Dictionary (2013). Charlottesville, VA: Unbound Medicine, Inc. PMID: None.

25. Thun MJ, Jacobs EJ, Patrono C (2012). The role of aspirin in cancer prevention. Nat Rev Clin Oncol, 9(5):259-67.

26. Vane, J. R., Botting, R. M (2003). The mechanism of action of aspirin Thromb. Res. 110, 255-258. 